\title{
Final Height of Patients with Pituitary Growth Failure and Changes in Growth Variables after Long Term Hormonal Therapy
}

\author{
E. JOSS, ${ }^{(14)}$ K. ZUPPINGER, H. P. SCHWARZ, AND H. ROTEN \\ Department of Pediatrics, University of Bern, Bern, Switzerland
}

\begin{abstract}
Summary
Eighteen patients with idiopathic growth hormone deficiency (GHD) were treated with human growth hormone (HGH) until cessation of growth. Half of these patients achieved a final height within 2 S.D. of the target height, the sex-corrected midparent height. Although growth data at the onset of therapy and during therapy were not different in the total and partial growth hormone deficient patients, the result of the latter was less favourable: eight of the 13 patients with total and only one of 5 with partial GHD reached a final height within parental target limits.

A longitudinal analysis of height and bone age in the males with total GHD showed a progressive improvement of the height standard deviation scores for chronologic age (SDS-CA) during 4 years of HGH therapy: from -5.6 to -3.8 standard deviation scores (SDS) with no influence on bone age SDS. After adding androgen therapy in order to induce puberty in the patients with additional gonadotropin deficiency, an increase of growth velocity from 4.7 to $6.3 \mathrm{~cm} /$ year was elicited. Height SDS-CA was improved by 1 SDS and bone age SDS advanced by 1.9 SDS.

Of the available methods for adult height prodiction calculated at onset of therapy, the Tanner method based on bone age best reflects the height that probably would be attained without therapy. HGH therapy initiated a clear increase in height prediction. Androgen therapy, in addition to HGH therapy, resulted in an additional small increase in the predicted height.

Final height achieved was significantly correlated with midparent height. Final height expressed in SDS of target height, accounting for the genetic background, was significantly correlated with the bone age deficit, with height SDS-bone age (BA) at onset of therapy, and with the increase in height velocity during the first year of HGH therapy. No correlations were found between final height expressed in SDS of target height and chronologic age, height SDS-CA at onset of therapy and pretreatment height velocity.
\end{abstract}

\section{Abbreviations}

BA, bone age

CA, chronologic age

GH, growth hormone

GHD, growth hormone deficiency

HGH, human growth hormone

SDS, standard deviation scores

SDS-CA, standard deviation scores for chronologic age

SDS-BA, standard deviation scores for bone age

TSH, thyroid stimulating hormone

Therapy with HGH for pituitary growth failure is quite successful in most instances. It constitutes a heavy medical and financial burden and must be carried out over many years, preferably until cessation of growth. Even though the treatment has been available now for more than 20 years (8) and many publications have appeared on this subject (9), final results are only now appearing in the literature $(2,3,13)$. The final height achieved is influenced by many variables, which might be of importance for the indication and guidance of therapy. The present report is an analysis of growth variables in five girls and 13 boys with idiopathic GHD, who were treated with HGH until growth terminated. Ten of the boys also obtained androgen therapy because of additional gonadotrophin deficiency. Changes in adult height prediction were longitudinally analyzed during HGH and androgen therapy. Not only HGH but also androgen therapy proved to be beneficial with respect to final height.

\section{PATIENTS AND METHODS}

The clinical and diagnostic data of the patients were previously published (13). None of the patients included in the present report suffered from organic hypopituitarism. Thirteen patients (11 males and two females) were classified as having total GHD and five patients (two males and 3 females) as having partial GHD as defined earlier (5). Eleven of the 13 patients with total GHD had additional gonadotrophin deficiency, eight had ACTH and six TSH deficiency. All five patients with partial GHD had isolated GHD. The growth data of the patients at onset of therapy are shown in Table 1. The diagnosis of GHD was based on plasma concentrations of growth hormone during stimulation tests (insulin, and arginine tolerance test), which were made according to our diagnostic criteria (6). Peak values below $2 \mathrm{ng} / \mathrm{ml}$ were classified as total GHD, and peak values between $2-7 \mathrm{ng} / \mathrm{ml}$ on three repeated tests were classified as partial GHD (5). Gonadotrophin deficiency was assumed when the patient did not spontaneously enter puberty in spite of a bone age of 14 years in boys and 13 years in girls.

Twelve of the patients were of Italian origin. The mean midparental height of all patients was $163.1 \pm 4.4$ which is $8.2 \mathrm{~cm}$ below the Swiss population standard; therefore, in order to account for racial and genetic influences, the final height was not only expressed in SDS of the Swiss population standard but also as SDS of the sex corrected midparental height, the so-called target height (11). Target height is calculated as follows:

male patients:

$$
\text { target height }=\frac{\text { father's height }+ \text { mother's height }+13}{2}
$$

female patients:

$$
\text { target height }=\frac{\text { mother's height }+ \text { father's height }-13}{2}
$$

One S.D. of the target height is $4.25 \mathrm{~cm}$. The target limits, that is \pm 2 S.D. of the target height, represent the normal range within 
Table 1. Clinical data in eighteen patients with growth hormone deficiency at onset of therapy ${ }^{1}$

\begin{tabular}{lcc}
\hline & $\begin{array}{c}\text { Total GHD } \\
(n=13)\end{array}$ & $\begin{array}{c}\text { Partial GHD } \\
(n=5)\end{array}$ \\
\hline Chronologic age (yr) & $12.2 \pm 3.3$ & $11.5 \pm 2.2$ \\
& $(6.9$ to 16.3$)$ & $(9.2$ to 14.5$)$ \\
Bone age TW2-RUS (yr) & $7.7 \pm 3.1$ & $8.7 \pm 1.7$ \\
& $(2.2$ to 12.2$)$ & $(6.2$ to 10.3$)$ \\
Bone age TW2-RUS (SDS) & $-4.3 \pm 1.6$ & $-3.0 \pm 1.3$ \\
& $(-7.9$ to -2.9$)$ & $(-4.9$ to -1.2$)$ \\
Height SDS-CA & $-5.8 \pm 1.7$ & $-5.2 \pm 1.4$ \\
& $(-9.9$ to -3.6$)$ & $(-6.7$ to -3.0$)$ \\
Height SDS-BA & $-2.3 \pm 1.3$ & $-2.9 \pm 0.8$ \\
& $(-4.8$ to -0.7$)$ & $(-4.0$ to -1.9$)$ \\
Height velocity $(\mathrm{cm} / \mathrm{yr})$ & $2.4 \pm 1.2^{4}$ & $3.9 \pm 0.9^{4}$ \\
& $(0.6$ to 4.5$)$ & $(3.2$ to 4.9$)$ \\
\hline
\end{tabular}

\footnotetext{
${ }^{1}$ Values given as mean \pm 1 S.D., range given in parentheses.

${ }^{2} \mathrm{GHD}$, idiopathic growth hormone deficiency.

${ }^{3}$ SDS, standard deviation scores; SDS-CA, standard deviation scores for chronologic age; SDS-BA, standard deviation scores for bone age.

${ }^{4}$ Statistically different (Student's $t$ test), $P<0.025$.
}

which adult height is expected because of the genetic bäckground. All height measurements were done with a Harpenden stadiometer. Height was expressed as SDS-CA and SDS-BA.

$$
\operatorname{SDS}=\frac{\mathrm{x}-\overline{\mathrm{x}}}{\text { S.D. }}
$$

where $\mathrm{x}$ represents the measurement; $\overline{\mathrm{x}}$, the mean height at the relevant chronologic age (respective bone age); and S.D., the standard deviation. The standards for height are those of the Zurich longitudinal growth study (7).

BA was estimated by the TW2-RUS method of Tanner (12). The SDS of bone age TW2-RUS was calculated from the published standards (12), whereby 2 S.D. were taken as the difference between the fiftieth and the third percentile. Predictions of adult height were calculated by the methods of Tanner (12), namely the chronologic-age-based and the bone-age-based system and by the methods of Bayley-Pinneau (1), and by the one of Roche-WainerThissen (10), which uses the bone age estimation of Greulich and Pyle (4).

The extrapolated height as an approximate estimation of the expected final height without therapy was assessed in patients with GHD and gonadotrophin deficiency by linear extrapolation of the pretreatment growth curve up to the age of their actual cessation of growth.

The HGH used for therapy during the first years was a preparation of Raben with a biologic activity of $0.9-1.8 \mathrm{IU}$ per $\mathrm{mg}$. Later on, a preparation of Zachmann, Zurich (extraction by Roos method) and finally Crescormon (Kabi) also extracted by the Roos method with a biologic activity of $1.2 \mathrm{IU}$ per $\mathrm{mg}$ were used. The dosage was approximately $10-12$ IU per $\mathrm{M}^{2}$ per wk in three divided intramuscular injections. The duration of therapy was 6.2 \pm 2.4 years (range 3.1-10.6 years). In no patient could GH antibodies be detected by radioimmunoassay. Patients with pituitary hypothyroidism were treated with $100-200 \mu \mathrm{g} \mathrm{1-Na-thyroxine}$ (Eltroxin, Glaxo) per day according to the serum thyroxine level, which was measured at half yearly intervals. Only one patient received $10 \mathrm{mg}$ hydrocortisone per $\mathrm{M}^{2}$ per day in three doses. The male patients with gonadotrophin deficiency received testosterone injections (Triolandren, Ciba) of $100 \mathrm{mg}$ for 3 months and thereafter $250 \mathrm{mg}$ intramuscularly once a month or $1500 \mathrm{U}$ human chorionic gonadotrophin (Pregnyl, Organon) three times per wk intramuscularly starting at the BA of approximately 14 years. The only female with gonadotrophin deficiency received $20 \mu \mathrm{g}$ cyclical ethinylestradiol per day and $5 \mathrm{mg}$ progesterone per day.

\section{RESULTS}

Final height. Values attained after long-term therapy in patients with total and partial GHD are given in Table 2. Although the growth data at onset of therapy (Table 1) and the duration of therapy were not different between the total and partial $\mathrm{GH}$ deficient patients, the results of the latter are less favourable: fewer patients with partial GHD reached final heights within the target limits.

Longitudinal analysis of height and $B A$. A longitudinal analysis of height and bone age in males with total GHD showed a progressive improvement of the height SDS-CA during the initial 4 years of HGH therapy from -5.6 to -3.8 SDS with no influence on BA SDS (Fig. 1A). After adding androgen therapy to induce puberty in the patients with additional gonadotrophin deficiency at a mean $\mathrm{CA}$ of $18.5 \pm 2.0$ years (range $15.3-20.8$ years), an increase in growth velocity from 4.7 to $6.3 \mathrm{~cm} /$ year was elicited (Fig. 1B, top pannel). Height SDS-CA was improved by one SDS and BA SDS advanced by 1.9 SDS.

Adult height predictions. In another approach to assess the effect of therapy on growth and skeletal maturation, longitudinal calculations of adult height predictions were done. Although all available prediction methods have not been designed for the estimation of final height in pathologic conditions such as GHD, the changes in prediction supposedly reflect the integrated change of longitudinal growth and skeletal maturation. An improvement in prediction would mean that growth over a certain period was high compared to BA progression. The four available methods for adult height prediction calculated at onset of therapy gave quite divergent results (Table 3 ). The Bayley-Pinneau method mirrored the height that was achieved with therapy, whereas the Tanner method based on bone age reflects the height that probably would have been attained without therapy, i.e., the extrapolated height. The Tanner method based on bone age is therefore best suited for our purpose, namely to continuously assess the effect of therapy on growth. The increase in height prediction with therapy over the predicted values at onset of therapy is depicted in Figure 2. HGH therapy initiated a clear increase in height prediction (Fig. 2A). Androgen therapy gave a further increase in the height prediction (paired $t$ test: $P<0.02$ ) (Fig. 2B).

The six patients with TSH deficiency supplemented with thyroxine reached final heights that were not different from those without TSH deficiency (mean final height as SDS of target height: -1.78 versus -1.84$)$.

Correlations of final height to growth variables at onset of therapy. These values were calculated in order to analyze the possible factors influencing final height. Final height was found to significantly correlate with midparental height $(r=0.67, p<0.01)$. In order to account for this genetic factor, all further correlations were calculated as final height expressed in SDS of target height with respect to growth variables at onset of therapy. Significant correlations were found with BA $(r=-0.51, P<0.05)$, with bone age SDS, with height SDS-BA, and with the increase in height velocity during the first year of $\mathrm{HGH}$ therapy (Fig. 3). The more retarded the BA and the less severe the height deficit with respect to the BA and the greater the growth response at onset of HGH therapy, the better was the final result. No correlations were found between final height and pretreatment height velocity, height SDS-CA and chronologic age at onset of therapy.

\section{DISCUSSION}

A satisfactory final result, defined as a final height within the normal limits with respect to the midparental height (target height \pm 2 S.D.) was achieved by half of the patients. These results are similar to the ones recently published by Burns et al. (2) showing that 31 of their 55 patients (mainly isolated GHD) had final heights above the third percentile of the British population standard. It also corresponds to the statement of Ranke et al. (9) estimating on the basis of height predictions that about $50 \%$ of 
Table 2. Final height in eighteen patients with idiopathic growth hormone deficiency after long-term human growth hormone therapy

\begin{tabular}{|c|c|c|c|c|}
\hline & \multicolumn{2}{|c|}{ Total growth hormone deficiency } & \multicolumn{2}{|c|}{ Partial growth hormone deficiency } \\
\hline & Males $(n=11)$ & Females $(n=2)$ & Males $(n=2)$ & Females $(n=3)$ \\
\hline \multicolumn{5}{|l|}{ Absolute value $(\mathrm{cm})$} \\
\hline Mean & 161.3 & 151.0 & 159.5 & 145.7 \\
\hline Range & $(152.6-167.7)$ & $(150.7-151.4)$ & $(151.0-168.0)$ & $(134.1-154.8)$ \\
\hline SDS of population standard ${ }^{2}$ & \multirow{2}{*}{\multicolumn{2}{|c|}{$\begin{array}{c}-2.4 \pm 0.6^{1} \\
(-3.6 \text { to }-1.4)\end{array}$}} & \multicolumn{2}{|c|}{$-3.3 \pm 1.8$} \\
\hline SDS of target height & & & \multicolumn{2}{|c|}{$\begin{array}{l}(-6.1 \text { to }-1.4) \\
-2.5 \pm 0.9\end{array}$} \\
\hline & \multicolumn{2}{|c|}{$\begin{array}{c}-1.8 \pm 1.0 \\
(-3.6 \text { to }-0.3)\end{array}$} & \multicolumn{2}{|c|}{$(-3.5$ to -1.0$)$} \\
\hline $\begin{array}{l}\text { Patients with final height within } \\
\pm 2 \text { S.D. of their target height }\end{array}$ & & & \multicolumn{2}{|c|}{1 of 5} \\
\hline
\end{tabular}

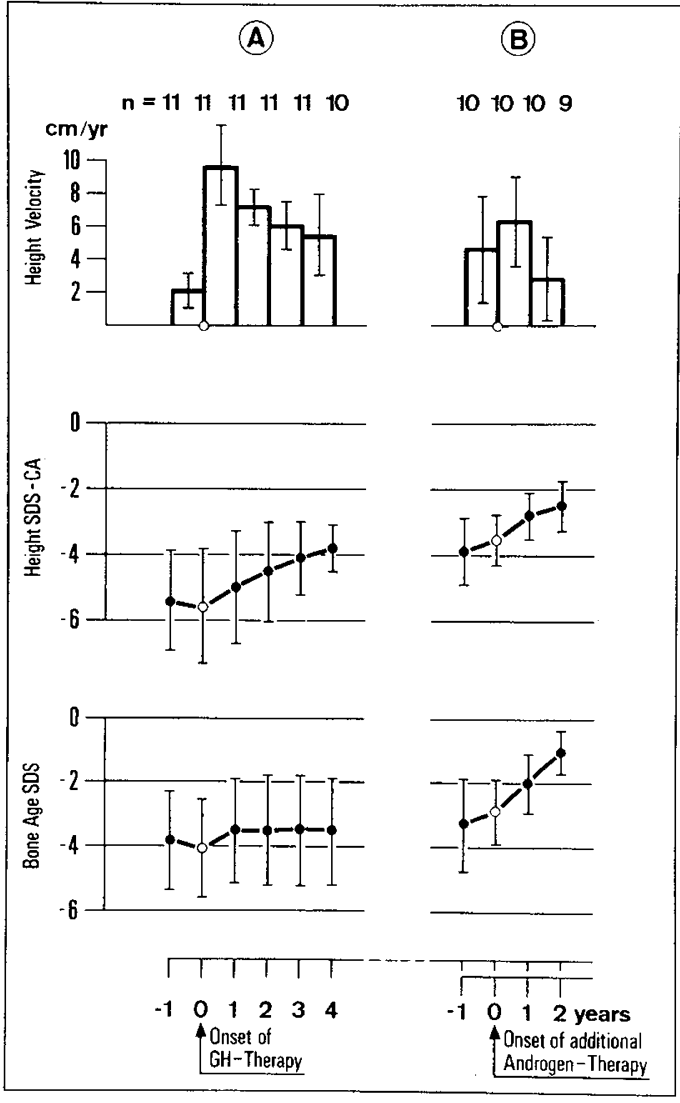

Fig. 1. Height velocity, height standard deviation scores (SDS) for chronologic age (CA), and bone age (BA) SDS in 11 boys with total growth hormone deficiency (GHD) under human growth hormone therapy and in 10 boys with total GHD and gonadotrophin deficiency under additional androgen therapy, mean \pm 1 S.D.

their patients would finally reach a height within normal limits. In spite of a very heavy financial burden and laborious longterm therapy by approximately 1000 intramuscular injections per patient almost half of them do not reach a fully satisfactory adult height. A retrospective analysis of the possible factors compromising an acceptable final height seems highly warranted.

Prognostically more important than Chronologic Age is Bone Age at time of onset of therapy. A large height deficit does not adversely affect final height if BA delay is of similar extent. The relatively late diagnosis resulting in severe height deficits in most of our patients with respect to their BA probably is an important factor for the relatively high percentage of unsatisfactory results. Nowadays, the diagnosis is made much earlier in most cases,
Table 3. Final height, extrapolated height and predictions of adult height at onset of therapy in ten boys with growth hormone and gonadotrophin deficiency

\begin{tabular}{lccc}
\hline & $\begin{array}{c}\text { Adult height } \\
\text { predictions } \\
(\mathrm{cm})\end{array}$ & $\begin{array}{c}\text { Final height } \\
(\mathrm{cm}) \\
161.6 \pm 4.7\end{array}$ & $\begin{array}{c}\text { Extrapolated } \\
\text { height }(\mathrm{cm}) \\
133.2 \pm 16.5\end{array}$ \\
\hline Bayley-Pinneau & $157.5 \pm 10.5^{1}$ & n.s. $^{2}$ & $(P<0.05)^{3}$ \\
Roche-Wainer-Thissen $^{2}$ & $156.3 \pm 6.2$ & $(P<0.05)^{3}$ & $(P<0.01)^{3}$ \\
Tanner, CA-based $^{4}$ & $149.2 \pm 6.9$ & $(P<0.01)^{3}$ & $(P<0.01)^{3}$ \\
Tanner, BA-based $^{4}$ & $132.6 \pm 15.6$ & $(P<0.01)^{3}$ & n.s. \\
\hline
\end{tabular}

${ }^{1}$ Mean \pm 1 S.D.

${ }^{2}$ Paired $t$ test for statistical analysis and n.s., not significant.

${ }^{3}$ Significant.

${ }^{4} \mathrm{CA}$, chronologic age and $\mathrm{BA}$, bone age.

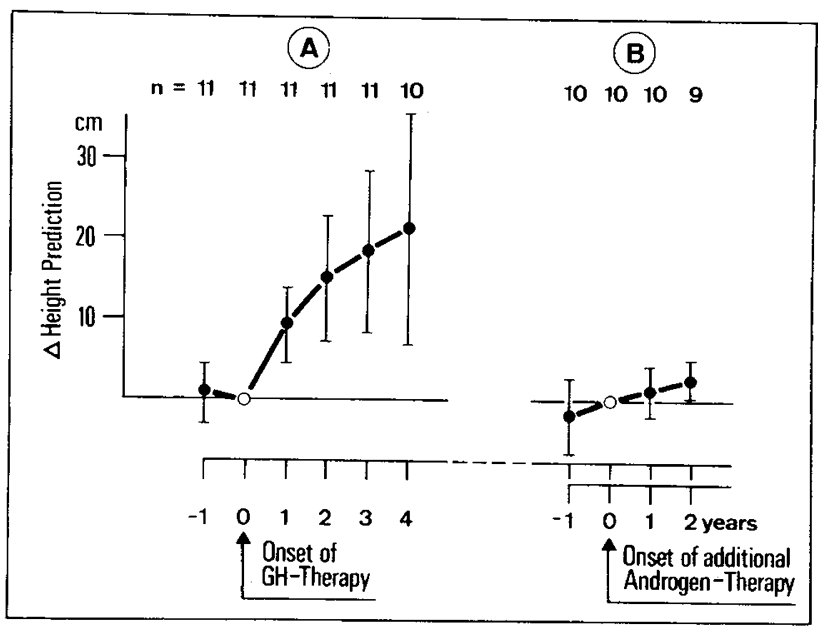

Fig. 2. Increase in final height prediction (Tanner method based on bone age) over the pretreatment value under human growth hormone and additional androgen therapy, mean \pm 1 S.D. Same patients as in Figure 1.

which will hopefully lead to better final results. The significant correlation between the final height and the delay in bone maturation is a strong indication that anabolic steroids should not be given during the early phases of hormonal therapy because of the risk of disproportionate acceleration of bone maturation. In the early phase of therapy height is strongly increased by $\mathbf{H G H}$ therapy without disproportionally accelerating bone maturation, thereby markedly improving final height prediction. The first year's response to $\mathrm{HGH}$ therapy is of prognostic value in our experience in contrast to the findings of Burns et al. (2).

The mean CA at onset of androgen therapy was $18.5 \pm 2.0$ years. In the patients in the study by Burns et al. (2) the onset was 


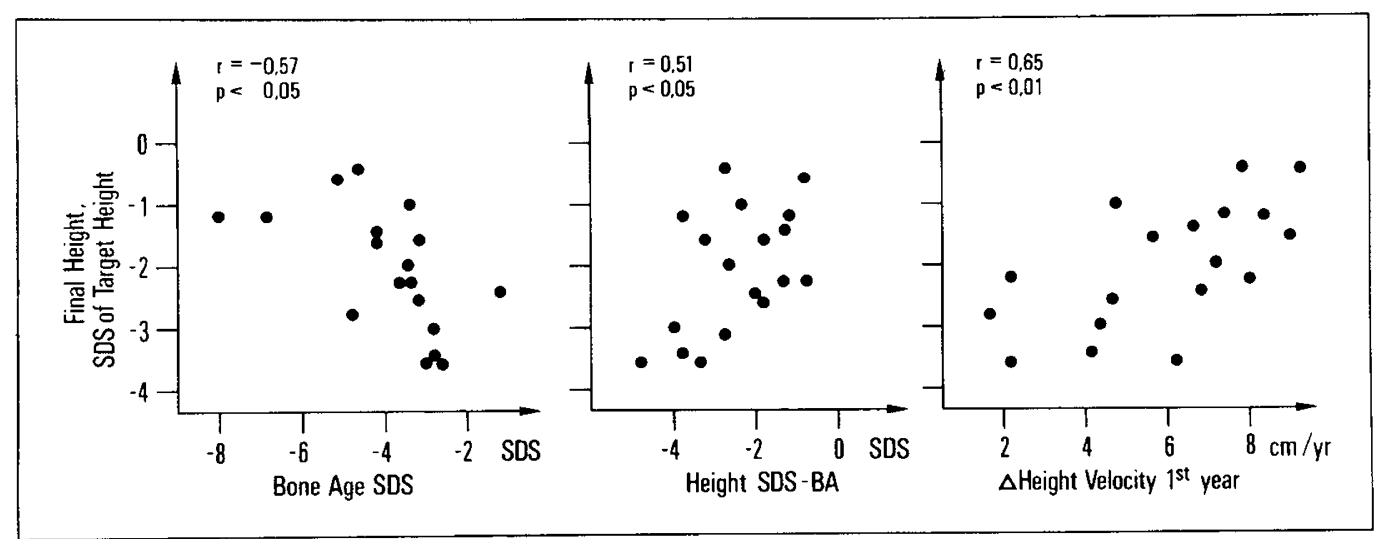

Fig. 3. Correlation of final height expressed in standard deviation scores (SDS) of target height to initial bone age SDS, height SDS-bone age (BA) and increase of height velocity during the first year of human growth hormone therapy. Correlations calculated with the Pearson test.

even later, namely at a mean CA of 20.4 years. The delay in our patients was due to the marked retardation of $\mathrm{BA}$, but also to a probably unjustified fear of deteriorating ultimate height by giving sex steroids. Yet height prediction in our experience was slightly improved by the addition of androgen therapy. The induction of puberty, therefore, should not be unduly delayed, keeping in mind that an appropriate timing of puberty is most important for optimal socio-sexual integration. Of the patients with gonadotrophin deficiency in our study none had taken up a stable relationship with a sexual partner at the time of final examination at which each one was older than 20 years. This could in part be due to the delay in sexual maturation and could possibly be changed by an earlier induction of puberty.

The overall gain in height by HGH therapy was obvious and estimated to be about 3.4 S.D. in total GHD and 1.9 S.D. in partial GHD. Among the methods of adult height prediction calculated at onset of therapy, the Bayley-Pinneau method mirrors best the height that finally was achieved with therapy. The Tanner method based on BA, on the other hand, was comparable to the extrapolated height and therefore reflects the height that probably would have been attained without therapy. This method gave the highest increase during HGH therapy. Whether these estimations represent actual gain by therapy remains highly speculative and should be analyzed in a greater number of patients. Nevertheless the observation of positive influence by androgen therapy on height prediction (Tanner method based on bone age) is a strong reinforcement to install androgen therapy in the males with gonadotrophin deficiency at a more appropriate age.

\section{REFERENCES AND NOTES}

1. Bayley, N. and Pinneau, S. R.: Tables for predicting adult height from skeletal age: revised for use with Greulich-Pyle hand standards. J. Pediatr., 40: 423

$$
\text { (1952). }
$$

2. Burns, E. C., Tanner, J. M., Preece, M. A., and Cameron, N.: Final height and pubertal development in 55 children with idiopathic growth hormone deficiency, treated for between 2 and 15 years with human growth hormone. Eur. J. Pediatr., 137: 155 (1981).

3. Burns, E. C., Tanner, J. M., Preece, M. A., and Cameron, N.: Growth hormone treatment in children with craniopharyngeoma: final growth status in 30 patients. Clin. Endocrinol., 14: 587 (1981).

4. Greulich, W. W. and Pyle, S. I.: Radiographic atlas of skeletal development of the hand and wrist, Ed. 2 (Stanford University Press, Stanford 1959).

5. Joss, E. E. and Zuppinger, K. A.: The significance of intermediate plasma growth hormone levels in growth-retarded children. J. Pediatr., 81: 1092 (1972).

6. Joss, E. E.: Growth hormone deficiency in childhood: Evaluation of diagnostic procedures. Monographs in Pediatrics Vol. 5 (S. Karger, Basel, 1975).

7. Prader, A., Issler, C., Molinari, L., and Largo, R. H.: Physical growth in Swiss children from 0 to 20 years of life (a longitudinal study). Helv. Paediatr. Acta., (In press).

8. Raben, M. S.: Treatment of a pituitary dwarf with human growth hormone. J. Clin. Endocrinol. Metab., 18: 901 (1958).

9. Ranke, M., Weber, B., and Bierich, J. R.: Long-term response to human growth hormone in 36 children with idiopathic growth hormone deficiency. Eur. J. Pediatr., 132: 221 (1979).

10. Roche, A. F., Wainer, H., and Thissen, D.: Predicting adult stature for individuals. Monographs in Paediatrics Vol. 3, (S. Karger, Basel 1975).

11. Tanner, J. M., Goldstein, H., and Whitehouse, R. H.: Standards for children's height at ages 2-9 years allowing for height of parents. Arch. Dis. Child., 45: $755(1970)$.

12. Tanner, J. M., Whitehouse, R. H., Marshall, W. A., Healy, M. J. R., and Goldstein, H.: Assessment of skeletal maturity and prediction of adult height. (Academic Press, London 1975).

13. Zuppinger, K., Joss, E., Roten H., Schwarz, H. P., and Aebi, C.: Endresultate bei hypophysärem Kleinwuchs nach Wachstumshormontherapie. Schweiz. Rundschau Med. (PRAXIS), 69: 1197 (1980).

14. Requests for reprints should be addressed to: PD Dr. E. Joss, UniversitätsKinderklinik, Inselspital, CH-3010 Berne, Switzerland.

15. This research was supported by the Swiss National Science Foundation Grant No. 3.906- 0.77 and 3.439-0.74

16. Received for publication June 3, 1982.

17. Accepted for publication December 8, 1982. 